\title{
Erratum to: Oxidation behavior and kinetics of sulfide by synthesized manganese oxide minerals
}

\author{
Guohong Qiu • Qian Li • Ying Yu • Xionghan Feng • \\ Wenfeng Tan $\cdot$ Fan Liu
}

Published online: 16 September 2011

(C) Springer-Verlag 2011

\section{Erratum to: J Soils Sediments}

\section{DOI 10.1007/s11368-011-0381-0}

Due to an unfortunate mistake, the text of the Acknowledgments was not correct.

The Acknowledgements must read:

The authors thank the National Natural Science Foundation of China (Grant numbers: 41171375, 20807019 and 40830527), the Specialized Research Fund for the Doctoral Program of Higher Education of China (Grant number: 20070504053), and the Fundamental Research Funds for the Central Universities (Program number: 2011PY015) for financial support.

\footnotetext{
The online version of the original article can be found at http://dx.doi. org/10.1007/s11368-011-0381-0.

G. Qiu $\cdot$ Q. Li $\cdot$ Y. Yu $\cdot$ X. Feng $\cdot$ W. Tan $\cdot$ F. Liu $(\bowtie)$

Key Laboratory of Subtropical Agriculture Resource and Environment, Ministry of Agriculture, College of Resources and Environment, Huazhong Agricultural University,

Wuhan 430070, People's Republic of China

e-mail: liufan@mail.hzau.edu.cn 